\title{
Developing the Organized Village of Kasaan's First Steps Strategic Energy Plan
}

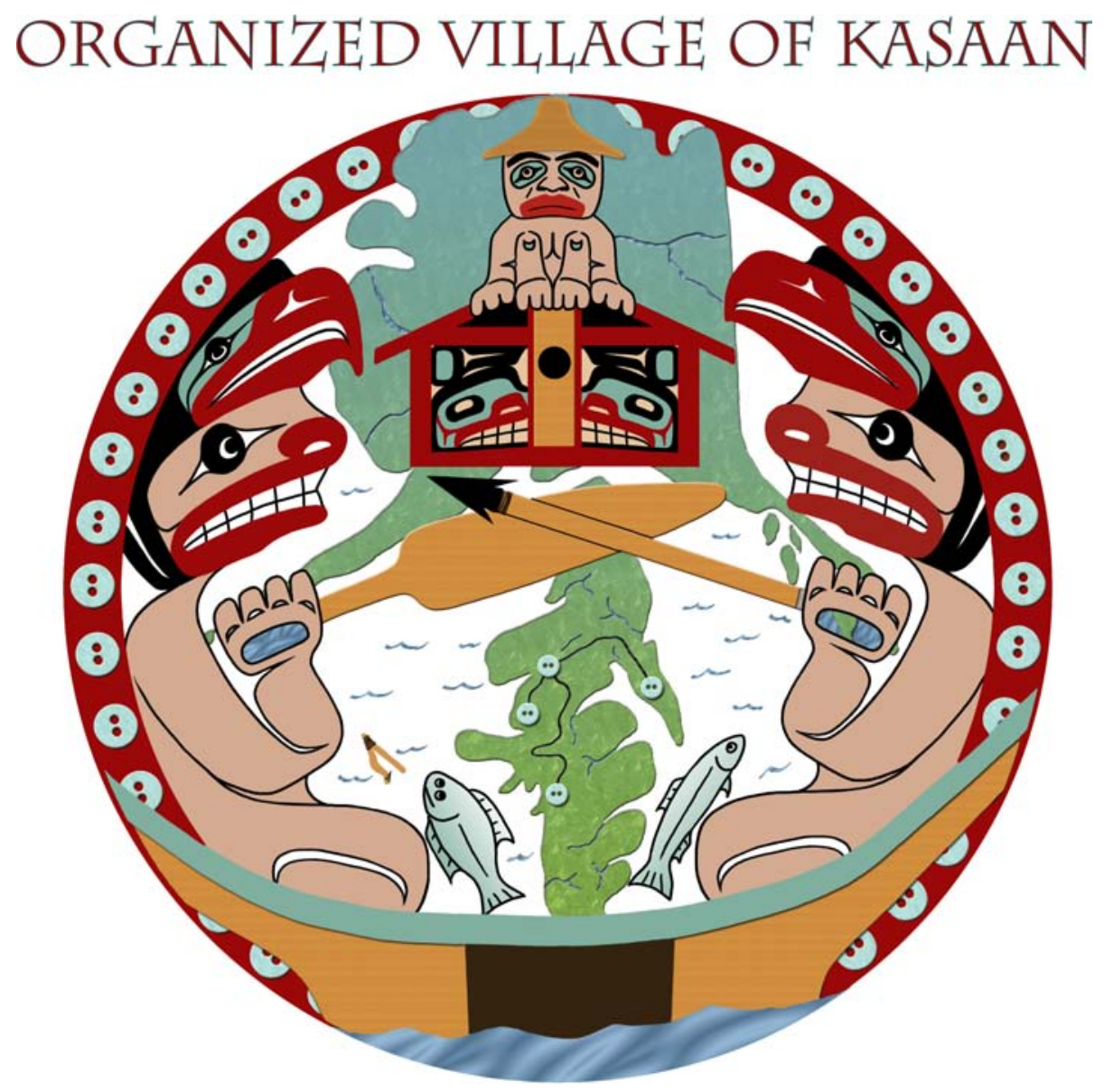

February 2013 


\section{Tribal Renewable Energy - Final Technical Report}

Recipient Organization: Organized Village of Kasaan

Project Title: Developing the Organized Village of Kasaan's Tribal Energy Plan

Award Number:

DE-EE0005050

Covering Period:

September 1, 2011 through December 31, 2012

Date of Report:

February 2013

Technical Contact:

Glenn "Stormy" Hamar, PO BOX 26, Kasaan

Alaska, 99950

phone: (907) 723-5020

email: stormy@kasaan.org

Partners:

Southeast Island School District, City of Kasaan, Kavilco corporation, Kasaan community members

DOE Project Officer: $\quad$ Lizana K. Pierce, (720) 356-1749, lizana.pierce@go.doe.gov

GO Project Monitor: $\quad$ Kris Venema, (720) 356-1352, kris.venema@go.doe.gov 


\section{Table of Contents}

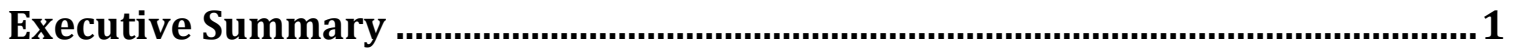

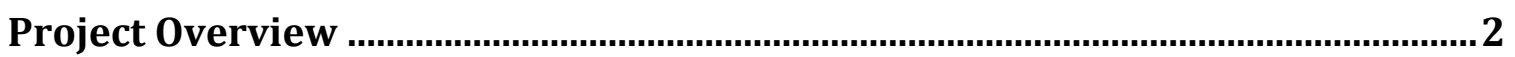

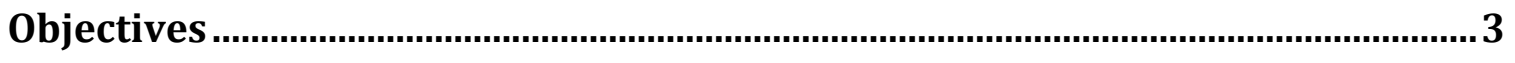

Description of Activities Performed................................................................4

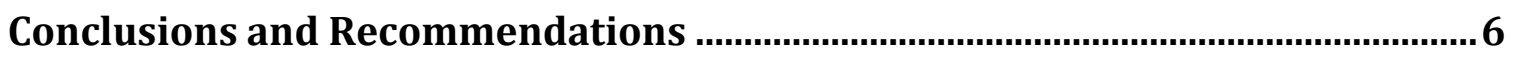

Lessons Learned..............................................................................................

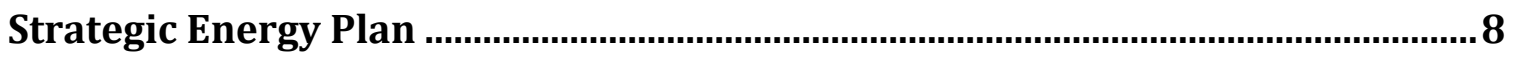

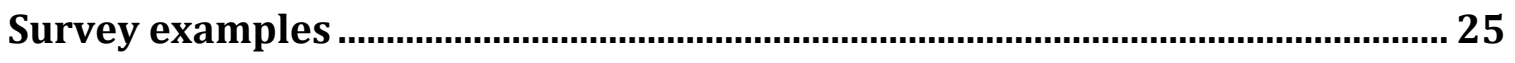

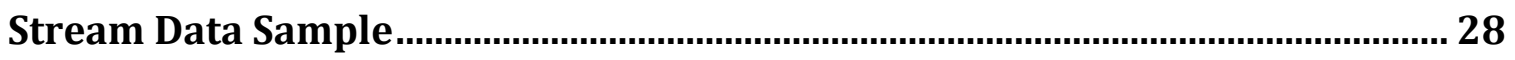

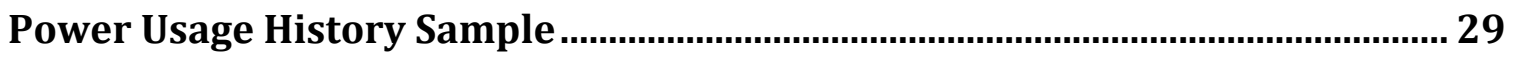




\section{Executive Summary}

The overall goal of the project was to bring our people closer together and increase the tribe's capacity and expertise on the subject of energy while developing a Strategic Energy Plan. The action steps of our strategic energy plan are the result of much research, discussion, desire, networking, both short and long term thought processes, experience, and our Haida culture. This was made possible by involving all stakeholders, including as many individuals as possible, as often as possible during the planning process.

The planning process involves many aspects that the tribe considers important to a successful plan, such as a project manager who has a strong interest in the area, thorough research, networking and discussion with all people to be directly affected or involved, and a health dose of our traditional Haida culture.

This project focuses on reducing energy costs and consumption as well as developing renewable energy sources. This plan is unique to the Organized Village of Kasaan and is designed to be as simple and clear as possible with significant and achievable goals. With the plan now in place, the Organized Village of Kasaan can begin to achieve healthy sustainability for our people.

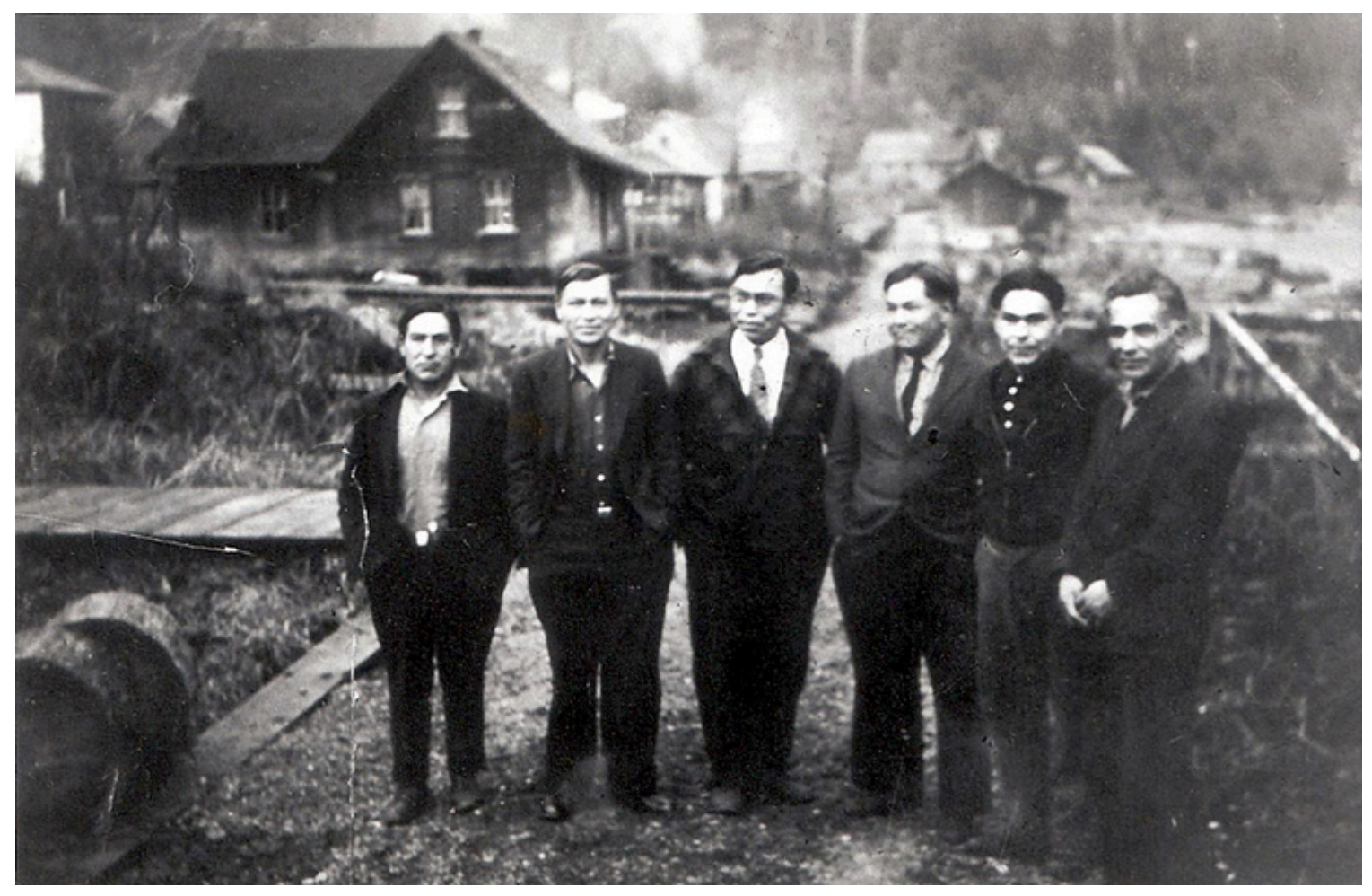

The first council of the Organized Village of Kasaan 


\section{Project Overview}

The Organized Village of Kasaan has a long-range vision of being economically and culturally self-sustaining; this has been a value of the Haida people for thousands of years. This is reflected in our energy vision statement:

"The Organized Village of Kasaan's energy vision is of a healthy, efficient, sustainable community, having our own renewable energy system which supplies Kasaan as well as other communities with reasonably priced power, improving the overall well-being of our area."

Important goals for the Tribe are reducing the Tribe's dependence on federal and state grants, and on energy sources that are owned and price-controlled by companies based hundreds of miles away. The creation of a Strategic Energy Plan focused on specific action steps. These steps include education and awareness, energy conservation and efficiency measures, as well as developing local renewable energy sources. This plan is a key element in the tribe's ultimate goal of healthy sustainability.

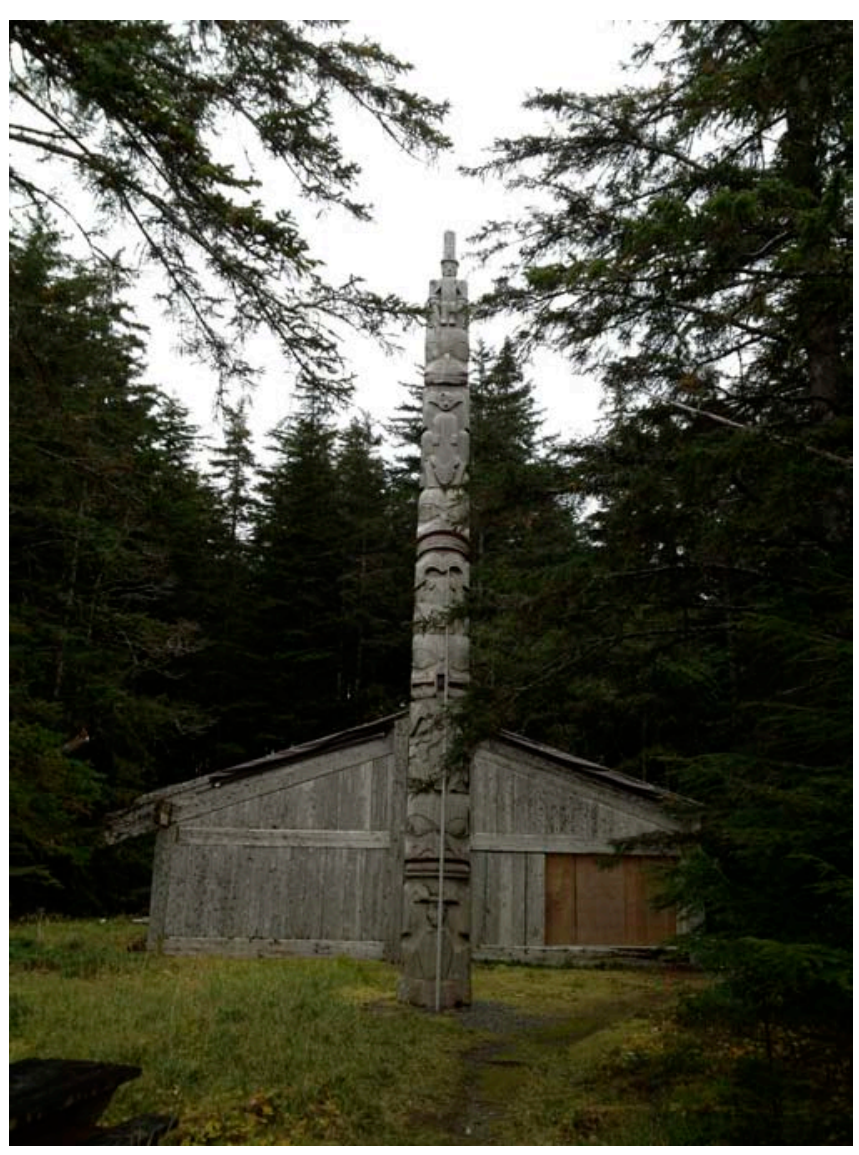

Kasaan's oldest building 


\section{Objectives}

Objective 1 - Develop a Kasaan Renewable Energy Network.

Objective 2 - Build Tribal capacity and expertise in the areas of alternative energy generation and reducing energy consumption.

Objective 3 - Develop a Tribal Energy Action Plan.

Objectives 1 and 2 were designed to generate the local data, information on relevant technologies, build local expertise and capacity, and obtain the stakeholder buy-in that was needed to complete Objective 3, the Tribal Energy Action Plan.

\section{Nearby energy potential as the seasons change}
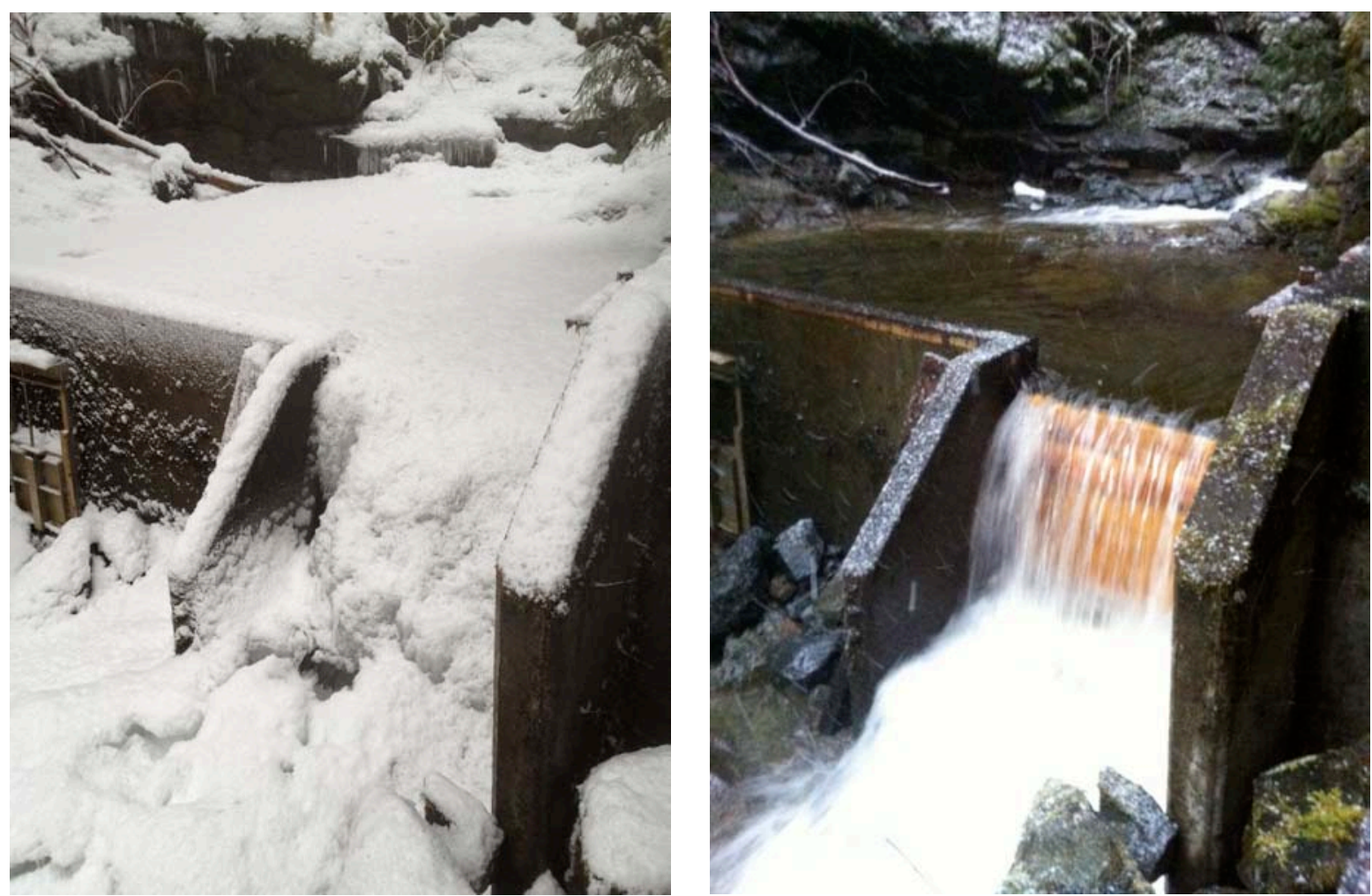


\section{Description of Activities Performed}

A local tribal energy champion was hired as our energy planner.

Much research was done on successful planning techniques, local energy use, available energy resources, energy technologies, and funding potential. Capacity building and increased expertise within the tribe has been a major factor.

Historical information on energy generation and use in our area was researched. Field research was done to identify any potential renewable energy sources.

Data was collected about past energy use of all types and there has been a lot of research and discussion on

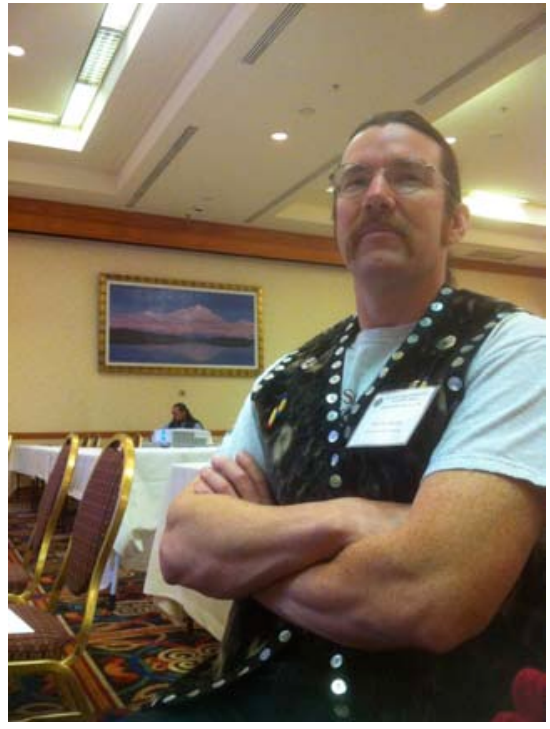
ways to improve our energy efficiency and conservation efforts as well as find potential renewable energy sources. Our tribe now has a much better understanding of our energy issues and is better suited to deal with energy matters.

Much research was also done to identify experts in the field of efficiency, conservation, and renewable energy. Experts in Alaska, the US and Canada were consulted. An energy expert from the Department Of Energy came to our village to make an assessment of hydro potential on a nearby water source, Linkum Creek.

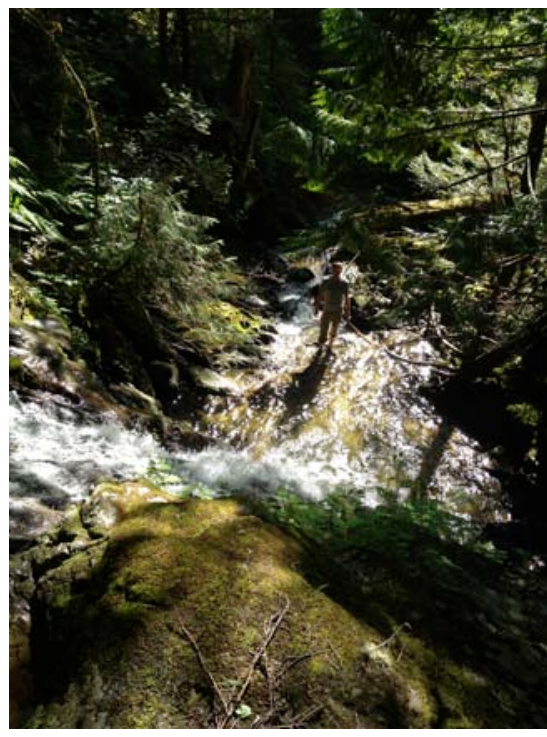

Several energy conferences were attended. These conferences were very valuable for networking as well as capacity building.

Stakeholders necessary to move potential projects forward were identified and contacted. These stakeholders consisted of our school district, Southeast Island School District, our city government, City of Kasaan, our village corporation, Kavilco Corporation, and each of our village residents.

These stakeholders were engaged in public meetings as well as individually surveyed, throughout the planning period. A thorough effort was made to get as much input from all stakeholders as possible.

Using all available information and experience, a written energy vision was developed to represent the desired direction of the stakeholders. 
Data from all sources, and all opinions, were given great consideration. Every effort was made to use this information to create an energy plan, which is understood by all, is accepted by all, and will be used by all. The plan was developed with the intent of being practical enough to achieve while significantly improving the energy conditions of the village in the coming years.

The final draft of the Strategic Energy Plan was approved by the tribal council and distributed to the stakeholders as well as potential future partners.

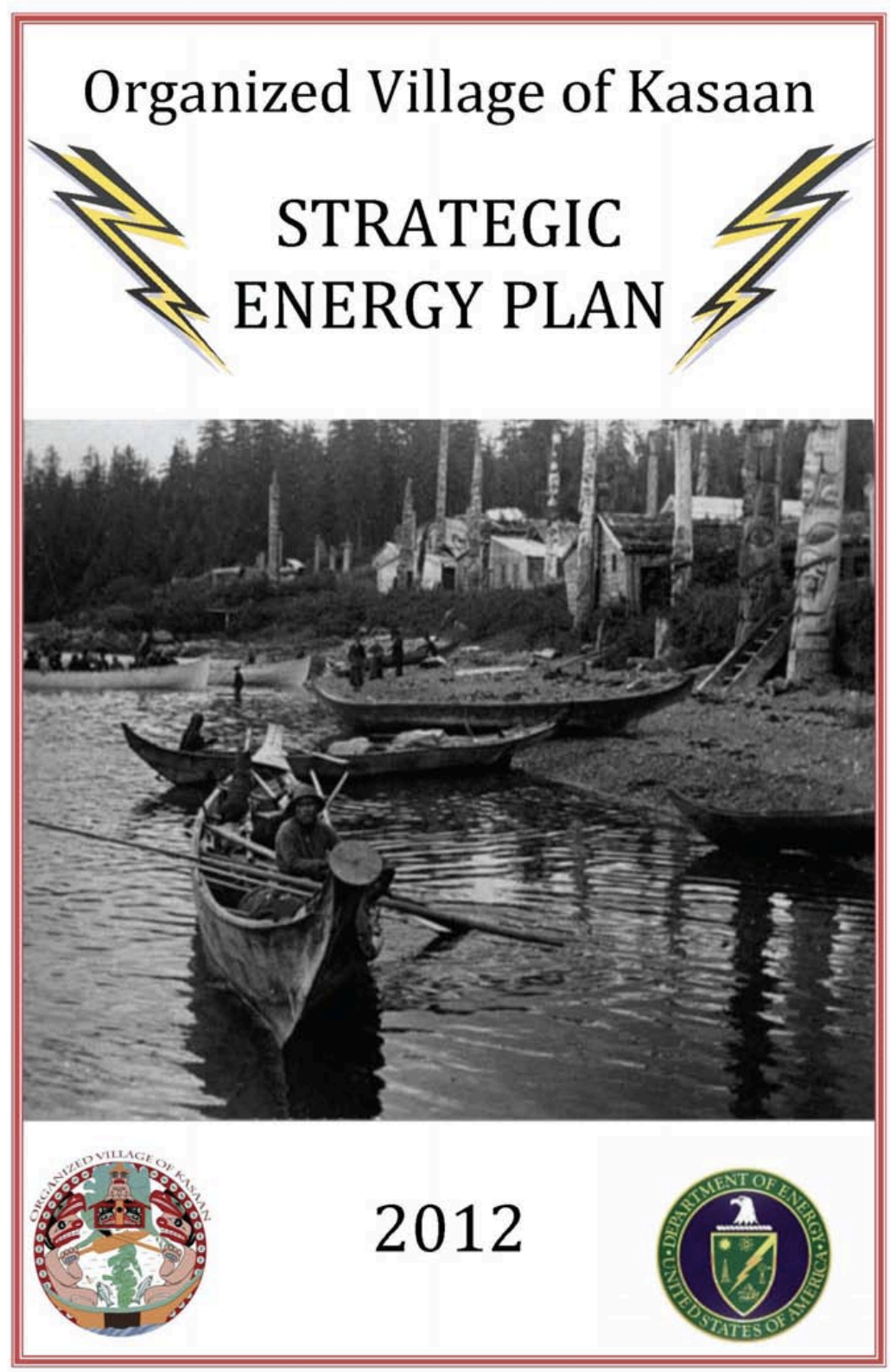




\section{Conclusions and Recommendations}

We have concluded that it is extremely important to develop our own energy plan. Make the plan for everyone in the tribe, and do it in such a way that everyone understands and supports it. The fancy plans sometimes created by professional plan writers often just sit on a shelf and take up space. It is important to consider all information available from energy professionals but also important to remember that they don't necessarily understand your situation as well as you do. Better things will happen if the plan is created with the help of all the people who will be directly affected. Believe in your people. We looked to our elders and ancestors often when considering the impacts of using different technologies.

We have concluded that a concentrated effort to consider the opinions of as many of our people as possible is necessary. We believe that the opinion and attitude of each and every person is important. We believe it is best to actively seek these opinions and feelings. It has been our observation in the past that just being available is not enough. For example, in the case of taking public surveys, even when surveys are mailed to each and every person, there is only a small percentage of people that reply. In our case the reason for taking a survey was to gain as much information as possible so we went door to door with a survey form and filled it out on the spot, taking as much time as necessary for everyone to voice their thoughts. This technique was very effective in not only gaining valuable information but it was also an opportunity to help bring awareness about energy conservation, efficiency and renewable energy possibilities to the people. This includes tribal council and staff members.

We have concluded that it is extremely important to involve the children as much as possible. We have learned that when the kids learn things they often teach it to their parents or other adults. These young people will soon be making the decisions and if we teach them now, we will all have a better future. We are very encouraged to see that our school just won a regional energy calendar contest put on by Tlingit-Haida Regional Housing Authority. This is a strong indication that our awareness efforts

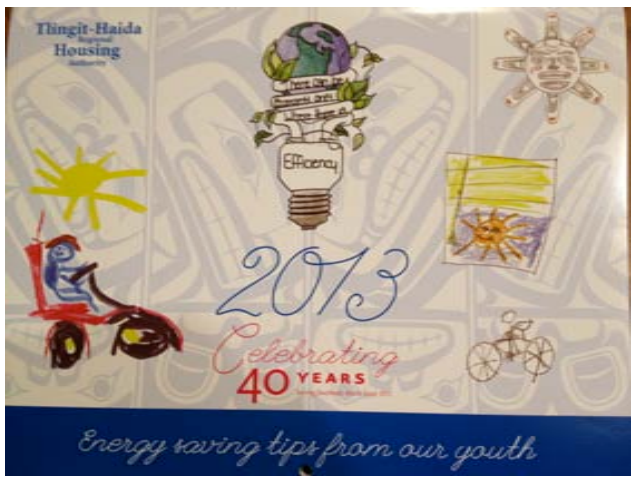
are making a difference.

We recommend using a well-balanced blend of new technologies and traditional cultural thought processes. Use a lot of long term thinking so your people can enjoy a healthy sustainable future.

Design your tribe's plan to be simple, easy to understand, and realistic.

To the Department Of Energy's Tribal Energy Program; we conclude that these planning grants are a very important part of your program and believe it is making a significant difference to not only the tribes but to the United States as a whole and we recommend continue the program as long as possible. 


\section{Lessons Learned}

Our tribe found this energy planning grant opportunity very useful in many ways. It helped us greatly to increase tribal capacity and expertise not only in the staff and council but in the membership as well. We found that awareness and understanding of energy issues was lacking amongst our people and while we initially made improvements in this area, we need to make a serious effort to further educate our people.

This awareness has already begun to make a difference, as we have decided to weatherize our office building with new windows, doors, windows, and cellulose insulation. Another example is the new clinic that is being built using cold climate building techniques and heated with an energy efficient heat pump. Our community use facility will be replaced with a more efficient design and will likely use a combination of wood heat and a heat pump.

We also found during our research that there was more historical data available than previously realized. We found that we actually have a good potential hydro project very near our village and now plan to develop it in the coming years.

Everyone from individual tribal members to tribal council and staff now has a much greater understanding of how and how much energy we use in our buildings and what we can do to reduce our usage. We also have a greater understanding of where our energy comes from and how we can change things for a healthier more sustainable future.

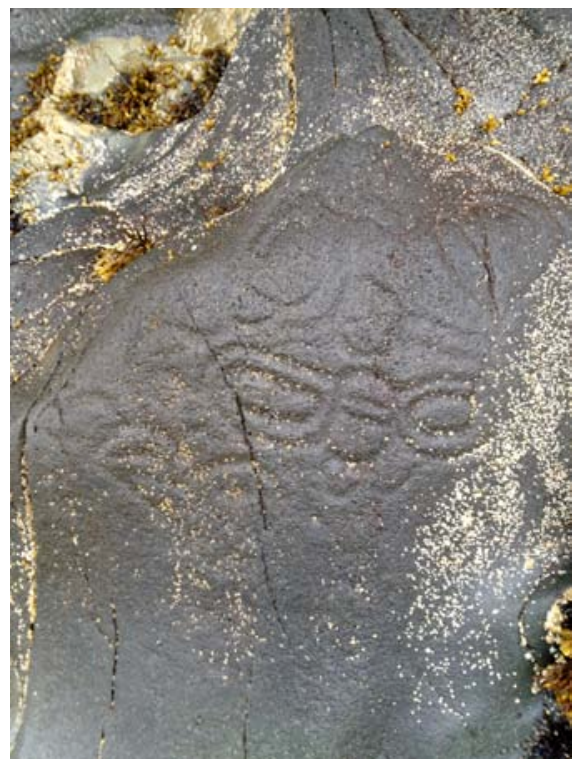

\section{Listen carefully to the messages of the ancestors.}

Appreciate the gifts of nature and allow them to prosper.

Respect all.

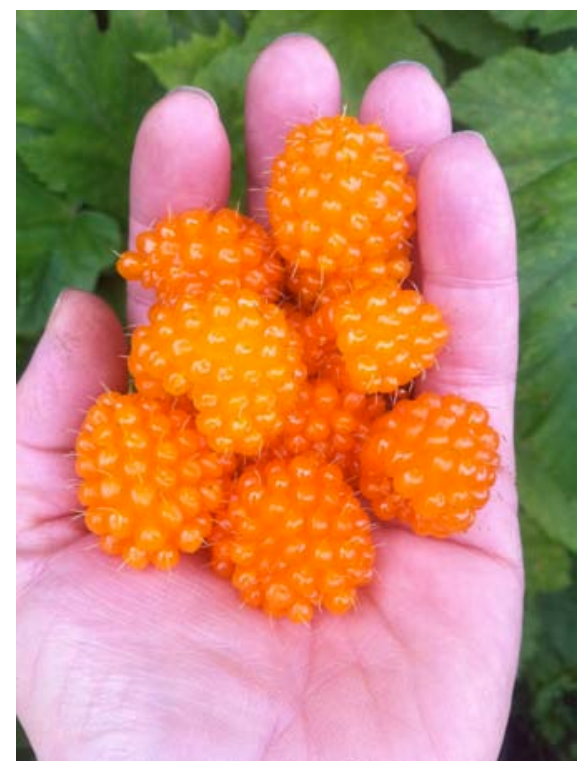


Strategic Energy Plan

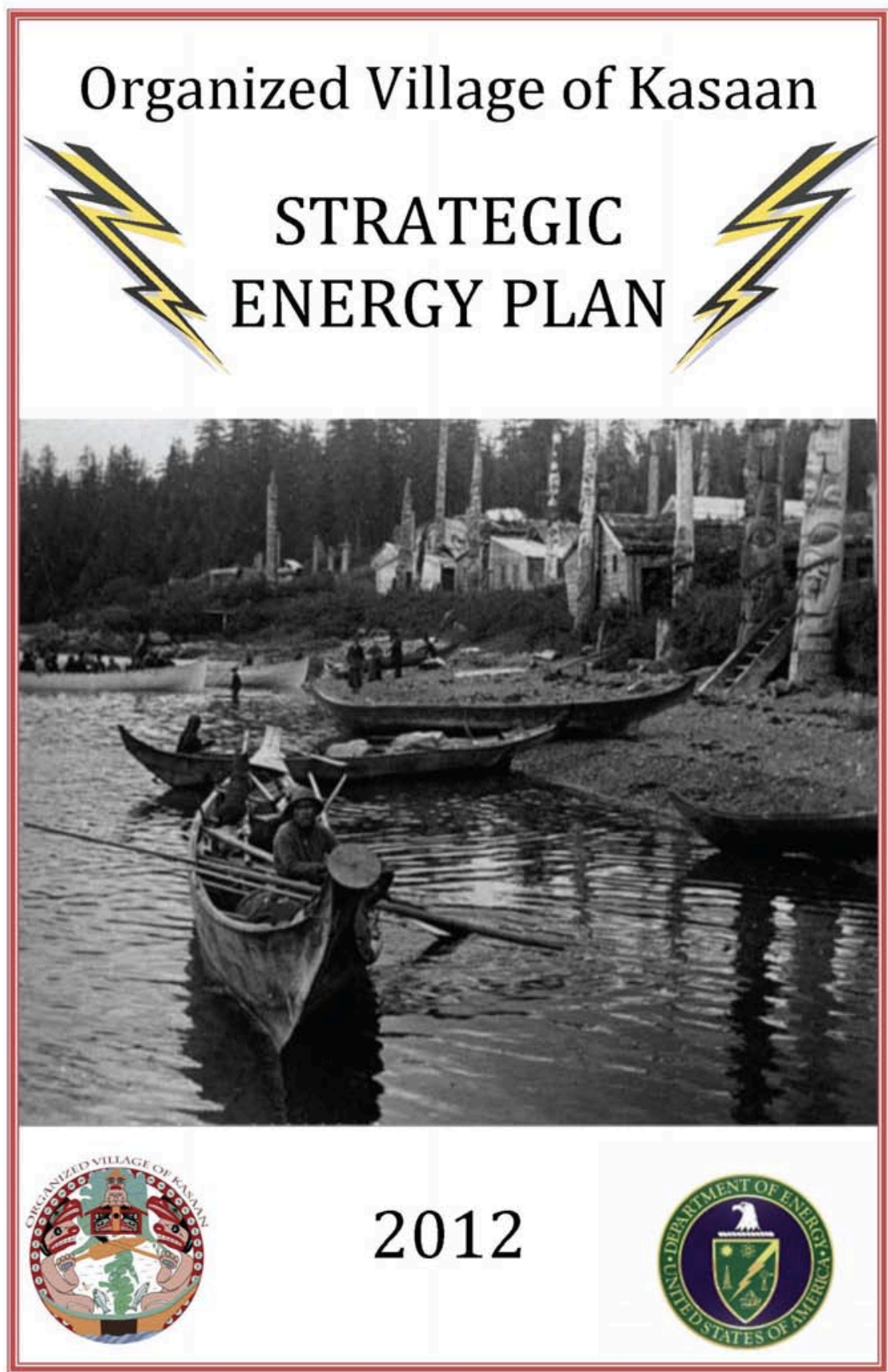




\title{
Adopted \\ November $21^{\text {st }} 2012$
}

\author{
Developed by the \\ Organized Village of Kasaan \\ with the help of a \\ "First Steps" Strategic Energy Planning Grant \\ from the \\ Department Of Energy's \\ Tribal Energy Program \\ Prepared by \\ Glenn "Stormy" Hamar \\ Organized Village of Kasaan \\ Strategic Energy Planner \\ Organized Village of Kasaan \\ PO Box KXA -26 \\ Ketchikan, Alaska 99950-0340 \\ 907-542-2230 \\ www.kasaan.org
}




\section{Table of Contents}

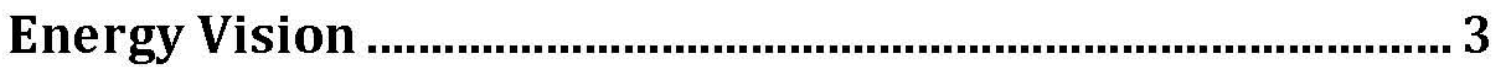

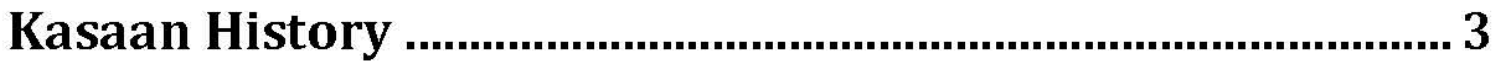

The foundation of the United States of America as it pertains to sustainability .......................................................... 4

The foundation or culture of the Kasaan Haida as it pertains to sustainability .................................................... 5

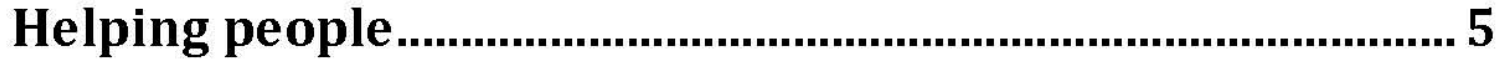

The energy demand of our buildings:..................................... 6

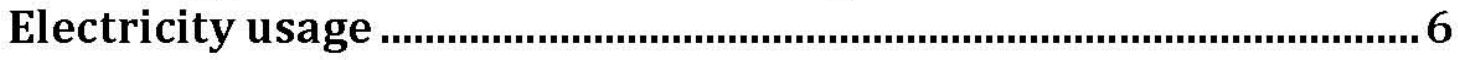

Diesel usage ........................................................................................

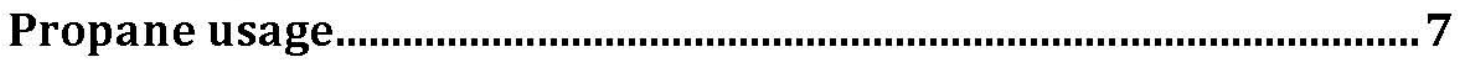

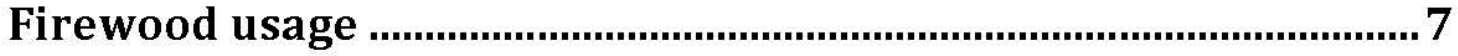

Total energy usage by our buildings ...........................................

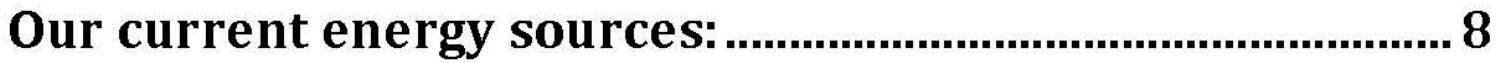

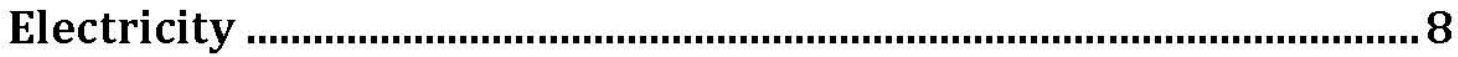

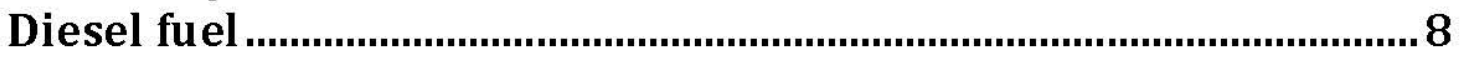

Propane

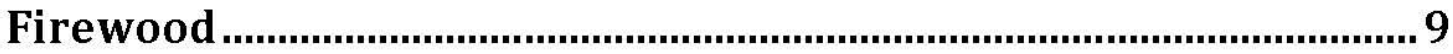

Community support:_..................................................................... 9

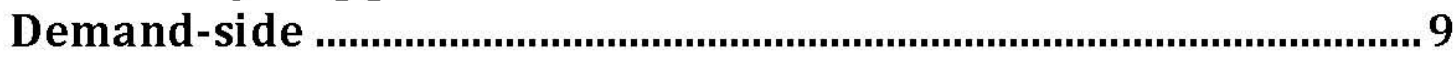

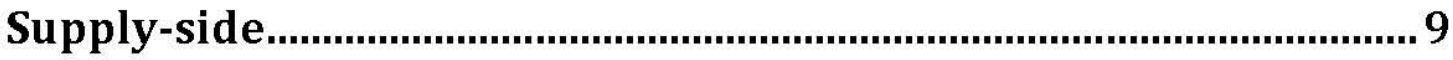

ACTION PLAN: ............................................................................10

Action Plan and supportive reasoning ................................10

Awareness, Conservation, Efficiency, Preparing for the future .. 10

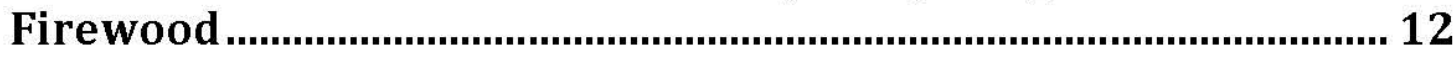

Hydropower................................................................................... 12

Benefits of Linkum creek hydropower .......................................................... 13

Wind, Solar, Tidal, Wave, Geothermal ............................................. 14 
11 


\section{Organized Village of Kasaan's Strategic Energy Plan}

\section{Energy Vision}

"The Organized Village of Kasaan's energy vision is of a healthy, efficient, sustainable community, having our own renewable energy system which supplies Kasaan as well as other communities with reasonably priced power, improving the overall well-being of our area."

The above energy vision as well as the following Strategic Energy Plan was developed according to the Organized Village of Kasaan's mission statement:

"To promote, preserve, and protect indigenous Haida identity and values for elders, youth and families by looking to the future in unity, developing economic opportunities, promoting education, and utilizing our cultural, natural and social resources."

\section{Kasaan History}

Kasaan, which is located on Prince of Wales Island, is the smallest of the four remaining Haida villages. Currently there are two villages in Alaska and two in Canada. When the Alaska - Canadian border was formed it caused some separation of the Haida Nation.

Our native people have an extremely lengthy history. A man's bones were found on this island in a cave along with several stone tools. The man's bones were proven to be over 10,000 years old and the tools were determined to have been made from multiple stone sources, some of which are located hundreds of miles away and can only be reached by water. This strongly suggests that at that time the people here were using canoes and already had extensive trade routes established. Additionally the Haida language is one of the few isolate languages in the world, further suggesting that our people have lived in the vicinity for much longer than 10,000 years. Some believe we have been here as long as the land has been exposed. The old Haida culture was possibly one of the best examples of human sustainability known to the modern world. 
The European movement brought many challenges to the Haida. Disease killed off $95 \%$ of the people, leaving the remaining $5 \%$ to deal with other introduced problems such as alcohol, missionaries, the United States Government and the cash economy. The new government and missionaries put every effort into destroying the Haida culture by taking the land, destroying the resources, burning the peoples villages, etc. It was plain to see that the new way of doing things was unsustainable.

Through all the turmoil the Haida tried to make the best of the situation, perhaps as they had many times throughout history. Many bad things happened and some of our old culture was jeopardized, but still, we remain, and still we understand how important our culture is to the sustainability of our people. We also know that the new world is upon us and that we must make the best of it, even though it clearly is not sustainable in it's current form. We will use our time proven traditional cultural thought processes when considering which steps to take as we move forward, so that we ensure the sustainability of our people.

\section{The foundation of the United States of America as it pertains to sustainability}

This energy plan was developed by careful examination of the past and present, with careful consideration of how action or inaction now, may affect the future. It is necessary to give further explanation about what we see when examining the processes of what we are calling our "old culture" and the "new world" so that all who read this plan can better understand the reasons we choose to do things in the manner that we do.

The blend of European cultures that created the United States of America were mainly land ownership cultures with a growth or conquering mentality. These cultures relied heavily on acquisition of new lands, as well as both natural and technological resources, to fund and strengthen their governments. This acquisition of lands and resources was generally at the expense of the previous inhabitants. This expense often came in the form of the death of these previously existing individuals, villages, and entire cultures.

There are two major fatal flaws with this type of system. One of these fatal flaws is the devastation which occurs to the native peoples of the area, destroying their sustainability. The other flaw is the simple fact that this type of system doesn't even account for its own sustainability, 
further creating a need for more and more resources. There is a finite amount of land and resources for the taking. The Organized Village of Kasaan realizes that if this continues, it will result in a resource deficit, which puts us all in an unhealthy situation.

In the conquest for more resources people began to travel to more new places, eventually leading to the extensive information transfer and resource use, of the modern world. Many amazing technologies have evolved from this process, many of which contribute to the need for even more and more resources. Infinite growth on this finite space we call earth is not a sustainable process.

\section{The foundation or culture of the Kasaan Haida as it pertains to sustainability}

We, the people of the Organized Village of Kasaan, desire to sustain our culture indefinitely into the future.

The old culture of the Kasaan Haida is time proven to be as sustainable as is possible on the earth. This Haida culture is based on a very strong interconnection with the surrounding earth and all its natural elements and life forms. Rather than to think of owning the earth and its many parts, we understand that we are in fact an important part of the natural environment.

A result of this acceptance and understanding of our place on this earth, is a deep respect. Our elders teach us from the time we are born that we need to use respect with all things. Respect is at the heart of our culture. Everything is important.

Historically our old culture thrived by using the surrounding resources in a respectful manner, this ensured that these resources wouldn't become depleted. As a culture, which is a part of nature, our dependence has been mainly on resources from our own traditional use area, with a relatively small reliance on trade items from distant places. Every resource was used at a renewable rate.

This very independent and sustainable system, otherwise known as our culture, is what guides our energy planning. In this modern blend of worlds we understand that energy in its many forms is extremely important and that we must manage its use carefully and with respect.

\section{Helping people}

We have a practice of figuring out how to get things done in our own village and then sharing what we know with other tribes so that they 
can develop their own projects. At the time of this writing we are building a small prototype clinic which will be replicated later in other small villages which, like us, aren't large enough to fit existing clinic programs.

Our desire is the same when it comes to energy. We see an opportunity to develop a local process that will result in a more efficient community along with the development of a small hydro project which will supply clean energy. We will strive to achieve these goals with the intent of passing along what we know to other interested tribes so that they can use the information to help their people improve their lives.

\section{The energy demand of our buildings:}

The main energy products used in Kasaan's buildings are electricity, diesel fuel, propane, and firewood.

Many building techniques have been used in Kasaan over time, from the old "longhouse" style or log cabins, to the trailer house or modular home. It is an interesting fact that in general the more modern our homes have become, the more energy consuming, less healthy, and less environmentally friendly they have become.

\section{Electricity usage}

The electrical consumption of the OVK's buildings has increased steadily at a rapid rate. Using over 13,000 kilowatt-hours in 2005, we have increased our usage by over $3000 \mathrm{kWh}$ per year, reaching over $33,000 \mathrm{kWh}$ for 2011. This year (2012) we used over 26,000 kWh just from January to March; this will be another record-breaking year for electrical consumption by the tribe. Our electrical bill for 2012 will probably be somewhere in the neighborhood of $\$ 13,000$ to $\$ 15,000$.

The electrical usage for the entire village is also steadily on the rise and amounts to about 190,000 kWh per year. 


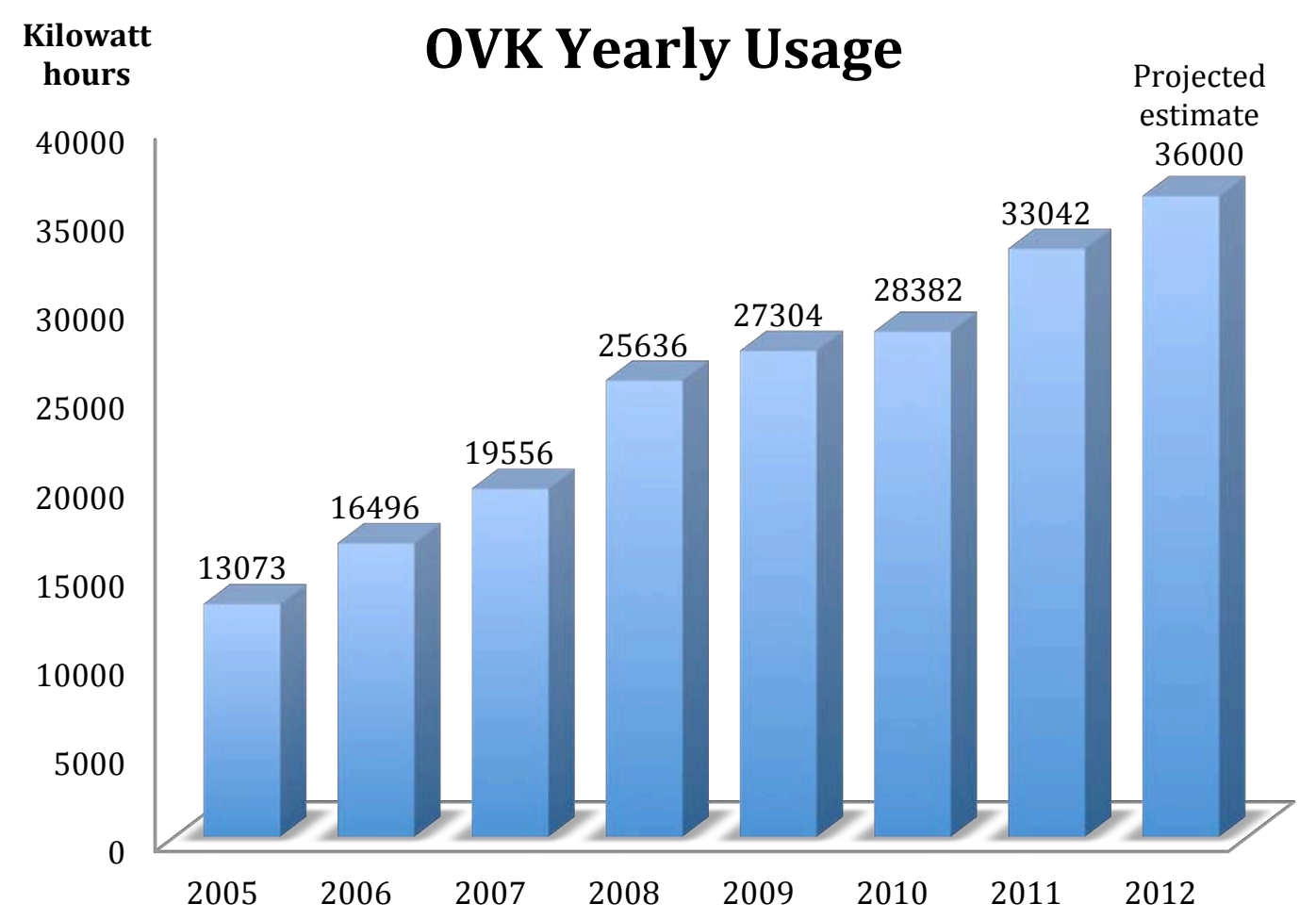

\section{Diesel usage}

The OVK spent over $\$ 8000$ dollars on heating oil during 2011. With the growth of the organization and the ever-increasing cost of diesel fuel this cost will escalate at an exponential rate in the coming years.

The village as a whole used approximately 10,000 gallons of diesel during the same period. When multiplying this by the current fuel price, we can see that the village may soon be paying as much for diesel as for electricity.

\section{Propane usage}

Propane usage in the village is reasonably low, although it may become more of a factor as diesel prices rise. The more inexpensive propane becomes ( relative to diesel) the more likely it is to replace diesel fuel, such as has already been done at the new OVK offices, as a heat source.

\section{Firewood usage}

Firewood is used by most households. Most users cut their own wood at a relatively low price but there are others who spend several hundred dollars per year on firewood. There are even some who spend over $\$ 1000$ per year on firewood. 
At this time firewood is actually giving our people the highest heat return on investment (or biggest bang for the buck).

\section{Total energy usage by our buildings}

The OVK is spending over $\$ 20,000$ per year on energy for its buildings.

Residents are spending an average of $\$ 3000$ to $\$ 4000$ per household each year on energy for their homes. Some are spending much more.

The village as a whole is spending $\$ 100,000$ or more each year on energy for its buildings. Kasaan is almost totally dependent on outsiders for energy and we must send this money out of the village every year to our suppliers.

The community has been growing at a steady rate and will likely continue to grow, with even greater energy needs.

\section{Our current energy sources:}

\section{Electricity}

Currently the village of Kasaan is dependent on the Alaska Power \& Telephone Company for electricity that is produced by a combination of hydro and diesel generation.

Hydropower is produced at Black Bear Lake and South Fork, a few miles North of Klawock.

During the months of March and April the water level in the lake gets low and large diesel generators located in Craig must be used to supplement the system. AP\&T also has diesel generators in several communities for use as backup generation during power outages. Outages are a common occurrence, especially during the fall and winter months.

The electricity produced is fed into the Prince of Wales grid, serving seven communities. The eighth community, Naukati, will likely be connected to the grid in the coming year, which will further burden the already overworked system.

\section{Diesel fuel}

Diesel is trucked in from across the island where it is barged in from afar. 


\section{Propane}

Propane is trucked in from across the island where it is also barged in from afar.

\section{Firewood}

As previously implied, firewood is obtained by the user directly or bought commercially and trucked in from various locations on POW.

\section{Community support:}

In the interest of developing an energy plan that will draw optimum support, the community has been surveyed individually as well as in public meeting to find out what the general consensus is on the subject of both demand-side and supply-side energy issues in Kasaan.

\section{Demand-side}

Most people are interested in having their homes weatherized, with new windows, doors, and insulation. Many homes are poorly insulated and some aren't insulated at all. Residents dislike paying so much in energy bills, with some having paid electricity bills of $\$ 400$ to $\$ 500$ monthly and others paying similar monthly heating fuel bills. The high cost of diesel is concerning everyone.

There is an apparent need for more education and awareness on the subject.

\section{Supply-side}

Most residents are very interested in renewable energy sources like hydro, wind, solar and tidal power generation. The main reason most people want renewable power is so we can be self-reliant and sustain ourselves rather than dependent on outsiders, especially in the case of natural or economic disasters. Some of the other reasons that people would like to see our community have its own renewable energy system are because they want to take better care of the environment, electricity could be cheaper and the system could be more reliable with less outages. There is also a strong interest in firewood utilization, such as wood fired boilers and better (drier) firewood for their wood stoves. 


\section{ACTION PLAN:}

\section{Action Plan and supportive reasoning}

This action plan addresses both demand side energy management and supply side renewable energy potential. These action steps are intended to improve energy conditions for the Organized Village of Kasaan, the Kasaan community as a whole, and ultimately the entire island of Prince of Wales and all of its communities.

Many energy conservation and efficiency options were studied as well as many renewable energy supply options. Upon careful consideration of all pertinent information, including the opinions of the community, scientific data, and the opinions of energy professionals, we have developed the following action steps toward a more healthy and sustainable future.

\section{Awareness, Conservation, Efficiency, Preparing for the future}

Awareness is one of the most important things we can do to improve energy conditions in our village, both short and long term. When people understand their situation they can make good decisions and take appropriate action.

\section{Promote the teaching of the AK EnergySmart K-12 Energy Efficiency Curriculum. Discuss energy at every Advisory School Council meeting.}

The kids will make the decisions of the future. In the mean time they will just naturally teach their parents and grandparents the things they learn in school about energy. Our current recycling program is a good example of this phenomenon.

2. Create an energy section in the library and promote it in various ways, such as posting notices in the community or announcing it at public meetings. Gather all information possible on the subject of energy.

Using energy conservation and efficiency measures on existing buildings is the quickest way to save energy and money. It is important that people have this information available so that they can learn it and make informed decisions.

Examples of energy conservation might be shutting off the lights immediately after use, or it could be shutting off the coffee 
pot and putting the coffee in a thermos. Turning your water heater down to 120 degrees Fahrenheit is another good example.

Examples of energy efficiency might be things like replacing incandescent light bulbs with high efficiency LED lights using a fraction of the energy. Weatherizing (replacing windows, doors, insulating, sealing) or replacing older appliances with Energy Star rated appliances.

3. Post all notices of weatherization programs as they become available and hold community paperwork parties, getting all interested applicants together to fill out the necessary forms.

Often people won't use the different programs that become available because they don't understand or are intimidated by the process of filling out paperwork. Properly weatherizing our buildings and practicing good energy conservation and efficiency techniques can potentially reduce our energy costs by $30 \%$ to $50 \%$. Initial weatherization costs are generally paid back in energy savings in 3 to 5 years. This is a very big bang for the buck considering that the average household could potentially save over $\$ 1700$ dollars every year after the initial 3 to 5 year period. Village wide there could potentially be savings of $\$ 30,000$ to $\$ 50,000$ savings per year. Using this formula the OVK might save $\$ 6,000$ to $\$ 10,000$ per year if it properly weatherizes its buildings. These are all dollars that could be put to good use within the community or be used to improve the community in some way.

4. Discuss energy issues at all joint $0 \mathrm{VK} /$ city meetings.

This is a matter of awareness as well as participation and teambuilding, important for our energy success.

5. Promote, encourage, and facilitate if possible, energy efficient building designs on all new construction, striving for net zero or near zero buildings (buildings that use very little or no energy).

New builders, if using net or near zero designs can potentially save $\$ 3000$ to $\$ 4000$ or more per year on energy costs, for the entire life of the building. These buildings can be initially expensive to build but in the long term are much cheaper.

6. Design the new Community Use Center to be as efficient as possible. Use as much local material as possible, avoiding hazardous materials in the construction.

Use both local knowledge and professional help in the design, using long term thought processes. 


\section{Firewood}

1. Cut firewood in May for our elders so their wood has a chance to dry before the coming winter.

2. Seek funding to build woodsheds for everyone in the village, or otherwise facilitate the building of these woodsheds.

3. Continue to help facilitate the school districts wood fired boiler and greenhouse plans.

Firewood is a renewable energy source and its use should be encouraged and facilitated. Firewood can produce many more times as much heat when it is dry versus when it is wet. This means we can produce more heat with less wood, getting an even bigger bang for the buck.

\section{Hydropower}

1. Send a letter to the City of Kasaan, Kavilco, and Alaska Power $\&$ Telephone explaining the benefits of developing a hydro project on Linkum creek. Express our interest in working with them and ask for their support so that we can pursue funding for a feasibility study.

2. Invite these entities to meet in Kasaan to discuss possibilities moving forward.

3. Develop a written agreement between the Organized Village of Kasaan, the City of Kasaan, Kavilco, and Alaska Power \& Telephone to develop a hydro project on Linkum creek.

One of the main reasons residents want the project is independence. The OVK will likely be doing a majority of the work in the development of this project; therefore the controlling interest should remain with the OVK.

The City of Kasaan is one of the controlling influences of Kasaan. They also hold water rights on Linkum creek and their support is very important to this project.

Kavilco owns the land that Linkum creek flows over, their support is very important to this project.

AP\&T owns the electrical grid in Kasaan as well as on the whole of Prince of Wales Island making their support very important. Their support will likely be necessary when pursuing feasibility study funds from AEA. They have experience in developing hydro projects and they would be valuable as an active participant in the process rather than just supporting.

4. Pursue funding for a feasibility study. 
The Alaska Energy Authority (AEA) will likely put forth a solicitation for proposals during 2013. There may be other avenues such as the Department of Energy (DOE), USDA, ANA, or others that can fund a feasibility study. We will need to keep an eye out for potential funding and promote our project as much as possible.

\section{Reevaluate our plans each year when doing organization wide strategic planning. As the feasibility study becomes complete, the next steps in the process will become more evident and we will need to be pursuing funding for permitting, design and engineering, and construction.}

\section{Benefits of Linkum creek hydropower}

Linkum Creek is in many ways ideal for a hydro project. It is a run of the river project, meaning that there wouldn't be any giant dams that destroy miles and miles of real estate. There is no danger to the salmon because the project area is so steep that there aren't any fish.

Another benefit of this steep hillside is that water piped down a significant elevation drop (head) develops a very high pressure. Water flowing at higher pressures is capable of very efficient electrical generation using a very simple device, called a pelton wheel, attached to a generator. A nozzle directs high-pressure water at the pelton wheel (runner) causing it to spin the generator. There is no pollution.

Linkum Creek is capable of producing about 200 kilowatts of electricity. This is about four times as much as the village currently uses.

There are numerous other benefits to this project as well:

A. We can have sustainable electricity and operate independently if necessary.

For instance, if power lines blow down between Kasaan and Black Bear, our power will stay on. Increases in electrical rates from rising fuel prices could potentially be eliminated. Having an onsite hydro generator will ensure power security in the event of economic collapse or depression due to stock market crash, government meltdown, war, or any other reasons.

B. It will take the place of our diesel backup generators eliminating fuel costs and pollution.

C. It won't be as noisy as the diesel system and requires less maintenance.

D. It will still employ a local person part time to take care of things, much as happens now with the backup diesel generators. 
E. Since the village only uses about $50 \mathrm{kw}$ and the Linkum creek hydro plant could produce four times that amount, that means that $150 \mathrm{kw}$ could be continuously fed into the POW grid system, easing the load on the Black Bear lake hydro plant. This is very significant because Black Bear Lake is used as an energy storage facility. Currently the storage (water in the lake) runs too low in March and April to power the POW grid, which is why they run the big diesel guzzling generators in Craig every year during that time. As other communities, such as Naukati are connected to the grid in the near future, the demand on Black Bear lake will be even greater. With the Linkum creek plant easing the burden on Black Bear Lake year round, millions of gallons of water can be saved for the months when it is needed most. The Linkum creek plant offers a double benefit in this case by both contributing to the lake storage throughout the year, building it up for when it is needed, and by easing the load directly during March and April. This project is not only very important to Kasaan but is very important to the sustainability of the entire island.

F. This project is ideally sized and located for rapid permitting, design and construction. Many of the larger projects have all the associated larger challenges to go along with them and often take multiple decades to complete; many never make it to construction.

G. The powerhouse on the Linkum creek plant will be so near to the existing power lines of Kasaan that there will be a very minimal cost to connect the system to the existing grid. Most hydro projects are many miles from existing grids and the expense to run wire and connect can be a prohibitive factor. We would only need feet of wire, rather than miles.

H. There are old logging roads, which will facilitate construction, saving large sums of money.

I. In the long term this project will help stabilize electrical rates not only in Kasaan but across the island, whereas the current system, with ever rising fuel prices, will only continue to cost us more and more. Rate stabilization is a good investment in our future.

\section{Wind, Solar, Tidal, Wave, Geothermal}

\section{Collect information and have it available in the library for interested persons.}


- Wind and solar are worth keeping an eye on but at this time aren't worth pursuing on a village wide scale. On an individual building or household scale it may be worth considering, depending on the houses location. These systems can be expensive and maintenance intensive, taking a long time to get a return on the investment.

- Wave and tidal energy are also worth keeping an eye on but the technology still has a way to go before it will be feasible in Kasaan as an energy source.

- Geothermal energy may be a very good source of heat for our buildings as extracted from the environment by heat pump type devices. We are currently planning to use one of these devices in our new clinic and may also use one in our new community center.

- At this time no high heat geothermal sites have been found in the Kasaan area that are capable of producing energy on the community scale.

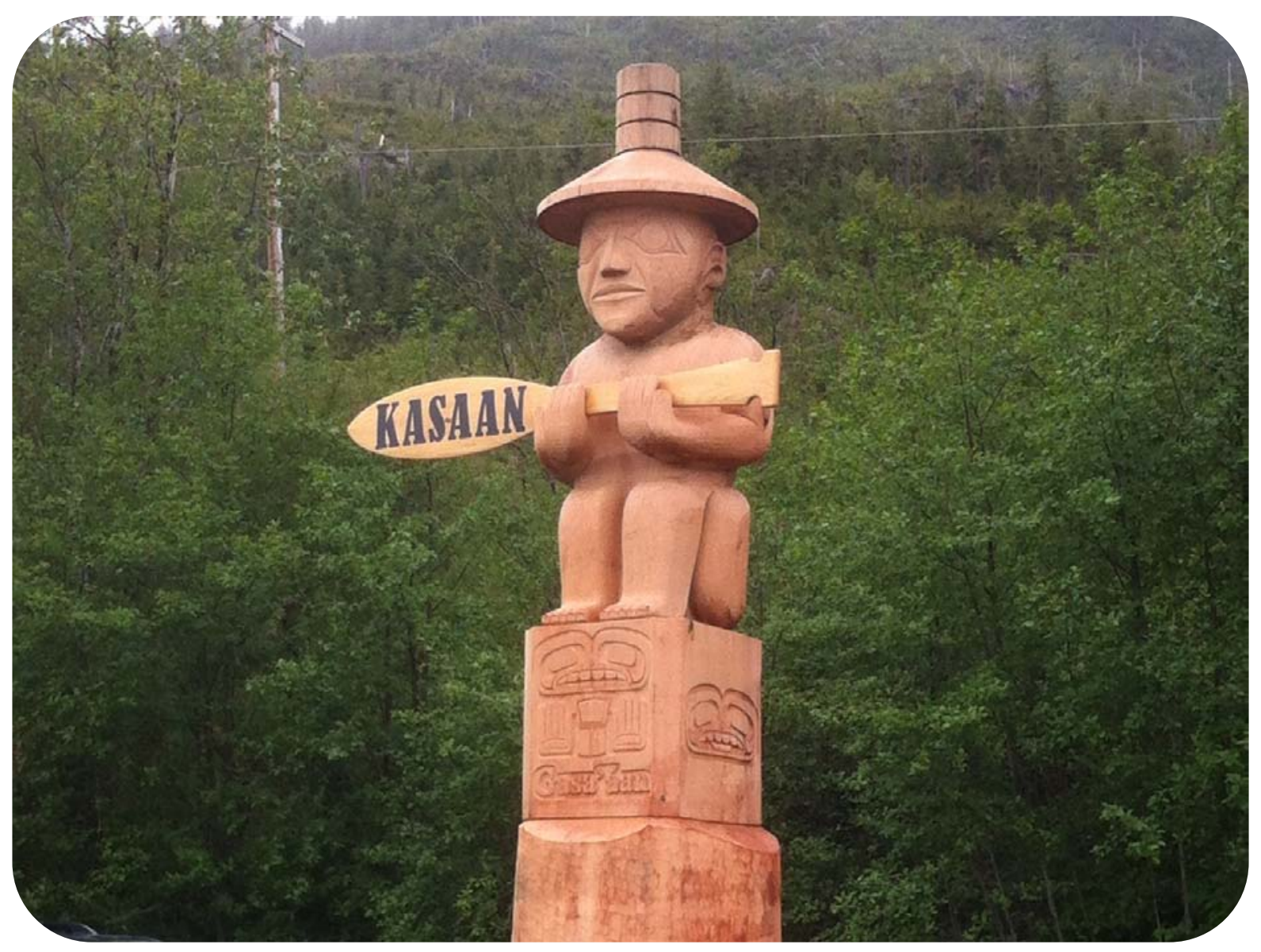




\section{Survey examples}

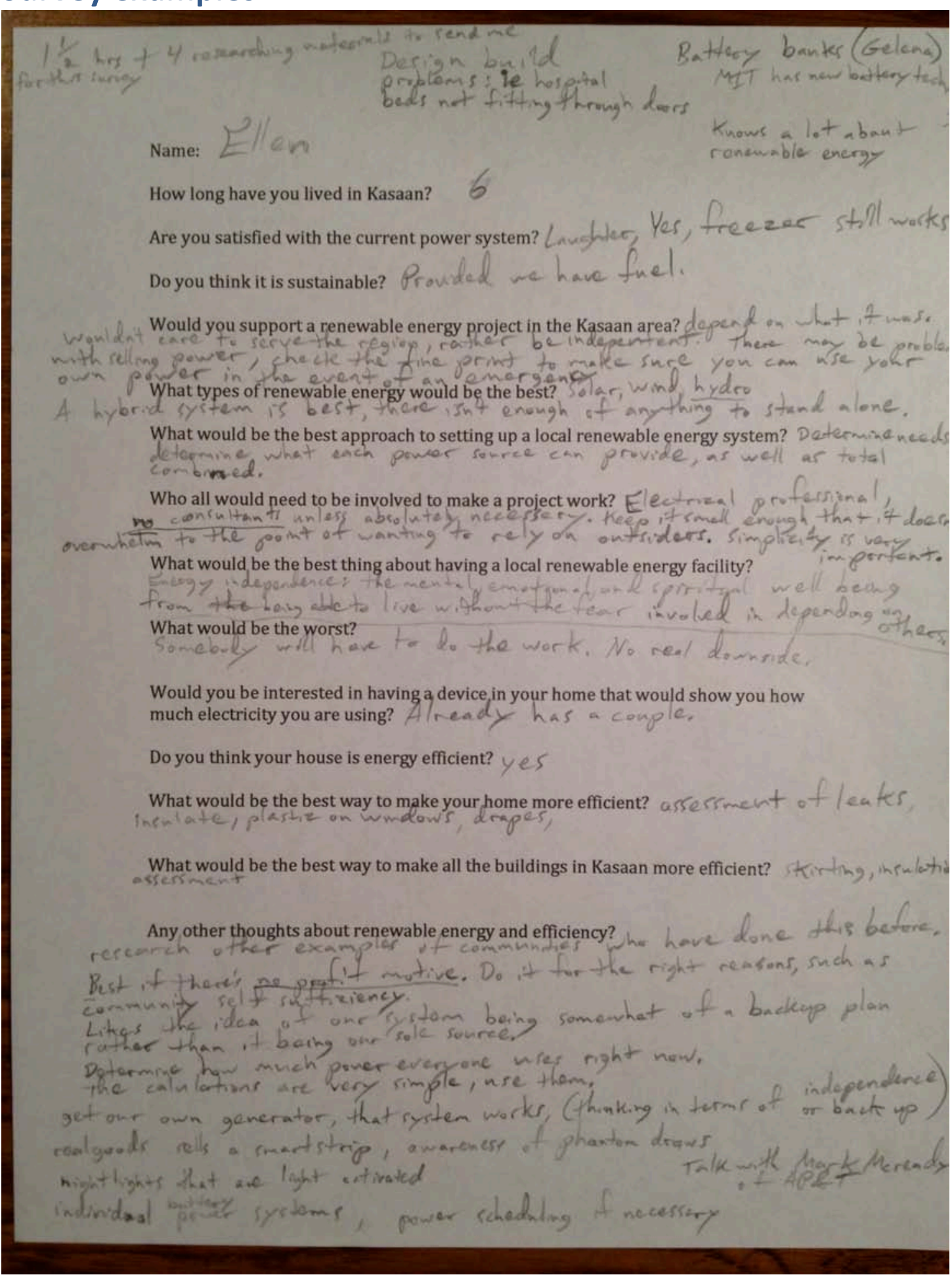




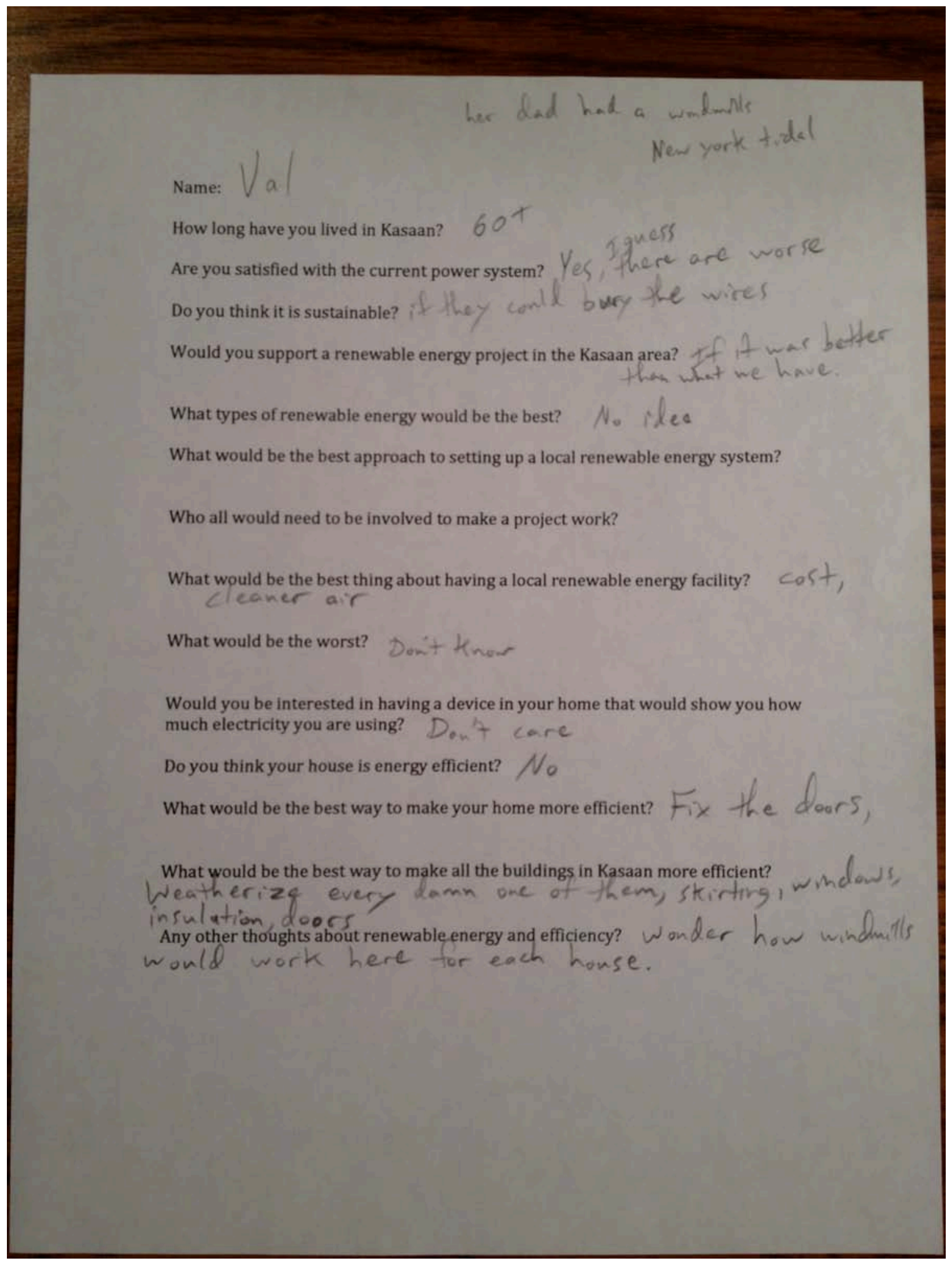


Name:

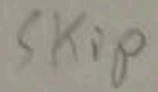

How long have you lived in Kasaan? 30.5

Are you satisfied with the current power system? pretty good, i, the it cheyper Do you think it is sustainable? If $A$ is taken care of

Would you support a renewable energy project in the Kasaan area? yes

What types of renewable energy would be the best? Hy dro

What would be the best approach to setting up a local renewable energy system? perim ts

Who all would need to be involved to make a project work? the city, thibe

What would be the best thing about having a local renewable energy facility? more con tre over the 5ystem.

What would be the worst? mateing sure you have enigngh money to maintain it, getting enongh peogle interested in If $^{2}$

Would you be interested in having a device in your home that would show you how much electricity you are using? yes

Do you think your house is energy efficient? No

What would be the best way to make your home more efficient? insula $t_{e}$

What would be the best way to make all the buildings in Kasaan more efficient? ins u lat $e$ and windows, doors, skirting

Any other thoughts about renewable energy and efficiency?

$$
\begin{aligned}
& \text { word biler,fuel cells } \\
& \text { companies an Lelforrind } \\
& \text { anits to poweechause } \\
& \text { Bellad Power }
\end{aligned}
$$$$
\text { Hy ho plat dregen }
$$$$
\text { jorge bateres }
$$ 


\section{Stream Data Sample}

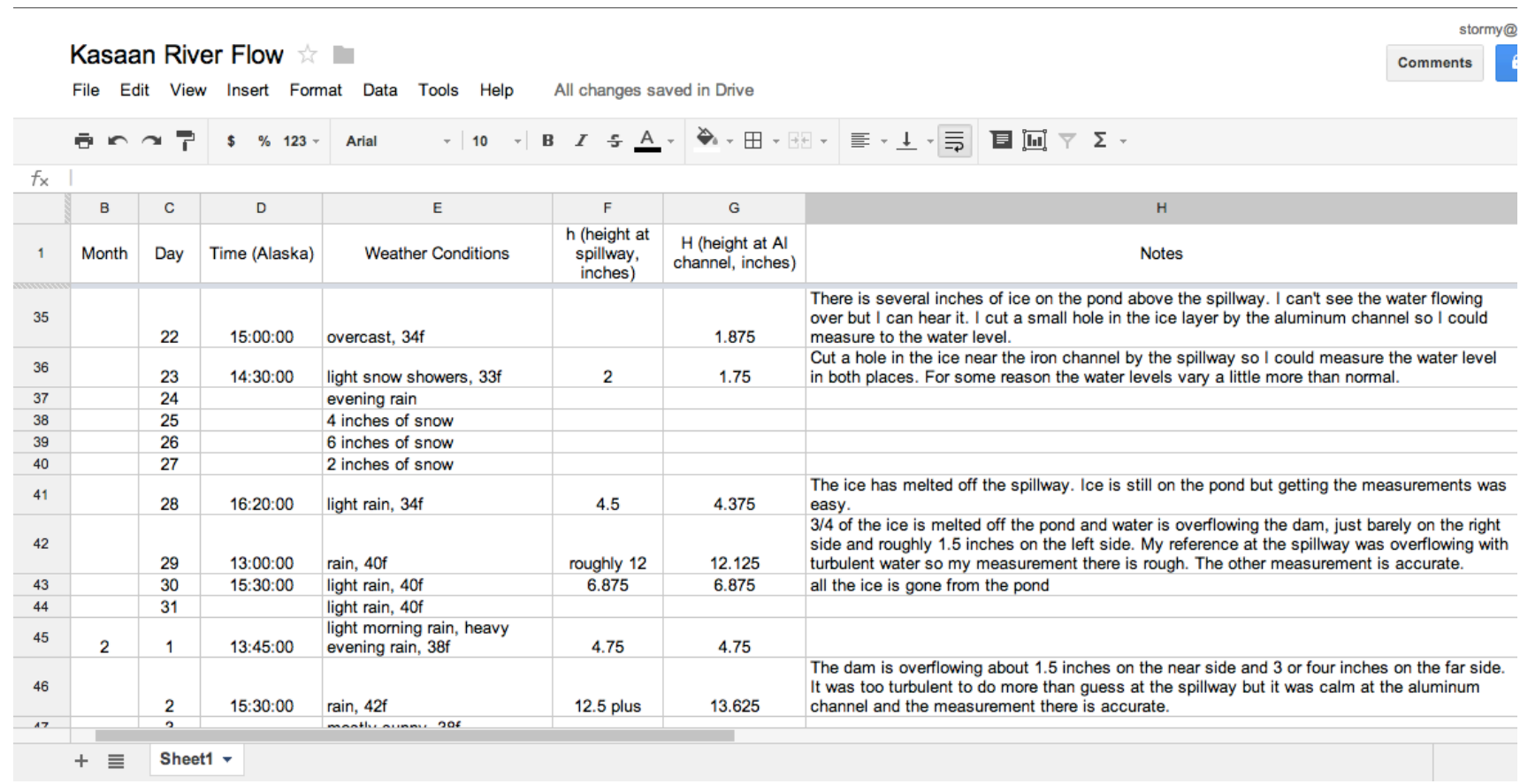




\section{Power Usage History Sample}

N

岁 COMMENTT: TP

Readiag Date Range: a101/2008 to eurremt

ACCOINT TYPE NAME TB0617 APC Alaska Power Company Ka: 05/20/2003 TB0617 TBO617 TB0617

TB0617

TB0617

TB0617

TB0617

TB0617

TB0617

TB0617

TB0617

TB0617

TB0617

TB0617

TB0617

TB0617

TBO617

TB0617

TB0617

TB0617

TB0617

TB0617

TB0617

TB0617

TB0617

TB0617

TB0617

TB0617

TB0617

TB0617

TB0617

TB0617

TB0617

TB0617

TB0617

는 $\quad$ TB0617

$\begin{array}{ll}\ddot{\sim} & \text { TB0617 } \\ \text { TB0617 }\end{array}$

TBO517

$\begin{array}{ll}\stackrel{N}{\vec{N}} & \text { TB0617 } \\ \stackrel{\mathrm{N}}{\mathrm{T}} & \text { TB0617 }\end{array}$

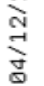

ALASKA POWER COMPANY DEMAND METER HISTORY REPORT

Power (arPWR) Billing

Current Active Accounts

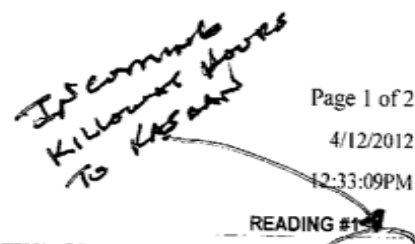

USE DEMAND* READ DATE*

METE.R USE 76290797
76290797 76290797 76290797

76290797

76290797

76290797

76290797

76290797

76290797

76290797

7629079

76290797
76290797

76290797

76290797

76290797

76290797

76290797

76290797

76290797

76290797

76290797

76290797

76290797
76290797

76290797

02906987

02906987

02906987

02906987
02906987

02906987
02906987

02906987

02906987

02906987

02906987
02906987

02906987

02906987

02906987

02906987

0290698

02906987

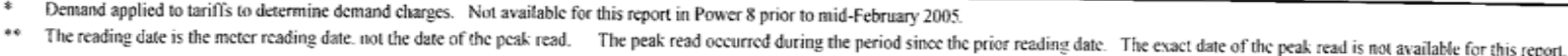

